\title{
Natural diamond growth conditions recorded by their internal structures.
}

\author{
Galina P. Bulanova ${ }^{1}$, Chris B. Smith ${ }^{1}$, Simon C. Kohn ${ }^{1}$ and Laura Speich ${ }^{1}$ \\ ${ }^{1}$ University of Bristol,Bristol,UK, galina_bulanova@hotmail.com;chris_b_smith@btopenworld.com; \\ simon.kohn@bristol.ac.uk; laura.speich@bristol.ac.uk
}

\section{Introduction}

Kimberlite and lamproite-hosted diamonds originate in a variety of lithospheric and sublithospheric mantle environments. They are thought to form by the reactions between fluids (derived from the asthenosphere or subduction processes) with mantle peridotite or eclogite over time from Archean to Proterozoic. We describe conditions under which such processes evolve (free or restricted space for growth, stable or dynamic systems, presence or absence of stress), as recorded by diamond growth structures and defects in the crystals observed by optical methods in polished central plates of diamonds. We analyse conditions of diamond formation in different mantle settings and investigate the dissimilarities in growth history of the diamonds and the spatial distribution of nitrogen $(\mathrm{N})$ content and model temperatures calculated from aggregation.

\section{Samples and analytical methods}

The internal structures of 250 octahedral or dodecahedral lithospheric macro-diamonds from Russian (Mir, Udachnaya, Aikhal), Zimbabwean (Murowa, Sese), Canadian (Diavik) kimberlites, and from Australian (Argyle) and Indian lamproites (Bunder) were studied. Additionally, 70 sublithospheric (SL) diamonds of more complex resorbed shape from Juina-5, Collier-4 kimberlites, Machado River alluvials (Brazil), and 30 diamonds of un-conventional lamprophyric origin from the Dachine komatiite (French Guyana, Smith et al., 2016) were investigated. All analytical work was done at the University of Bristol. The diamonds were polished along two parallel dodecahedral planes for production of central plates to reveal internal structures. Cathodoluminescence images were taken using a scanning electron microscope (SEM). Core-rim diamond traverses for nitrogen $(\mathrm{N})$ content and aggregation were performed using a Thermo iN10MX infrared microscope. Mineral inclusion compositions were determined by electron microprobe analysis.

\section{Results}

Most peridotitic (P) and eclogitic (E) diamonds from kimberlites have simple octahedral zonation (Fig 1a, b). Rarely, sectorial or cubic initial growth occurs, changing into octahedra in later stages.

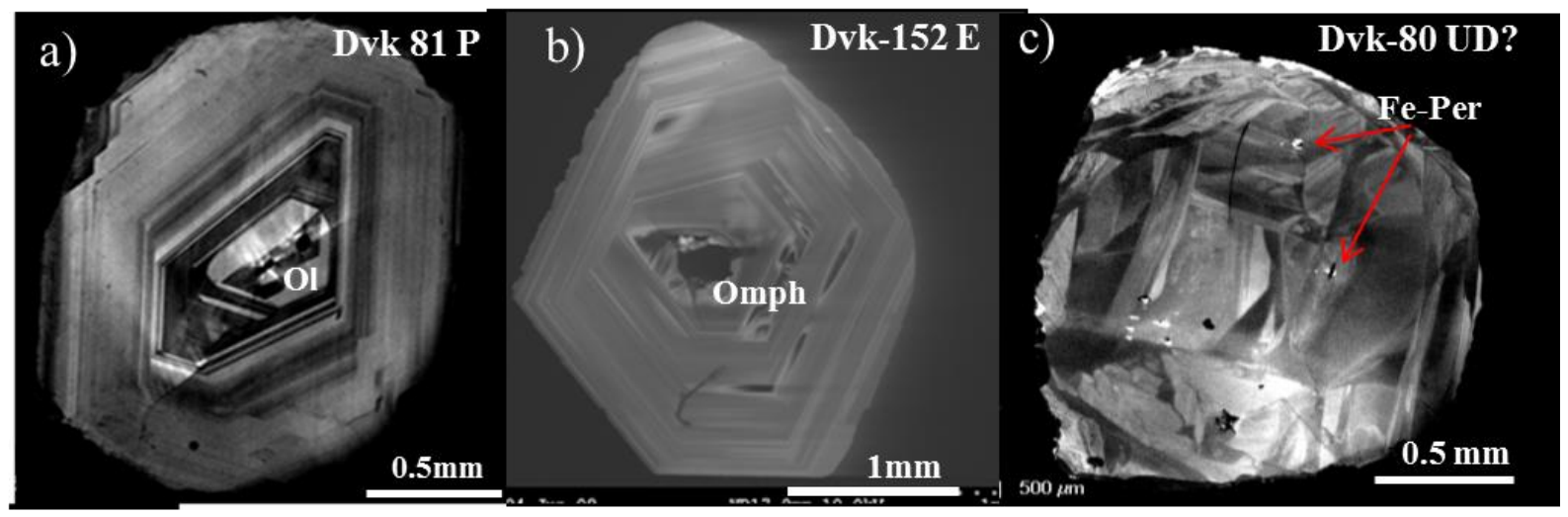

Figure 1: Internal zonation of diamonds from kimberlites (Diavik): a).Sharp octahedral zonation and external resorption of P diamond; b). Weak octahedral zonation in eclogitic crystal; c).Blocky texture of SL diamond. 
E diamonds from Argyle lamproites grew with narrow octahedral zones with minor internal resorption (Fig. 2a). Small Argyle P diamonds have sharp octahedral zonation (Fig 2b), but some of the larger, strongly resorbed $\mathrm{P}$ stones display sectorial growth as well (Fig. 2c).

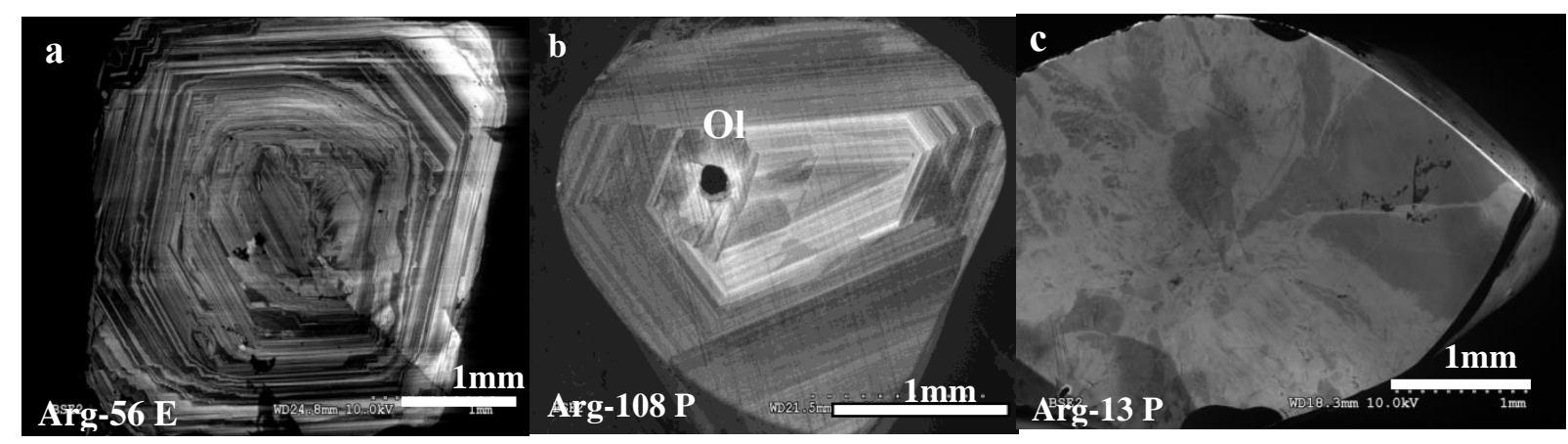

Figure 2: Internal morphology of diamonds from Argyle lamproites (explanations are given in the text)

Sublithospheric stones (Fig 3a, b and 1a) and Dachine diamonds (Fig. 3c) are characterised by very weak or lack of zonation, by complex internal structures, blocky textures, stress and internal cracks.

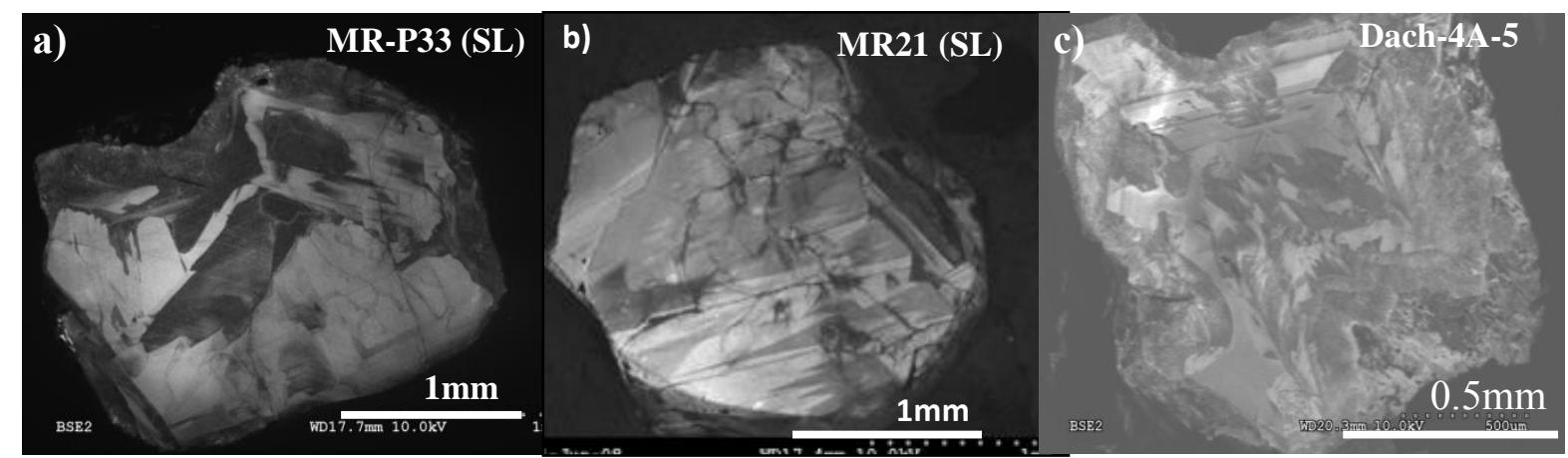

Figure 3: Internal structure of SL ( $\mathrm{a}, \mathrm{b})$, and unconventional (c) diamonds (see text for descriptions).

Argyle eclogitic stones and sublithospheric diamonds are the most defective, displaying brittle and plastic deformation, resorption and re-growth features. Thus the central zone of Arg pink-3 crystal is a broken diamond (Fig. 4a), giving an example of brittle deformation (see arrow in Fig.) taking place during crystal formation. Arg pink-2 eclogitic diamond shows octahedral zonation with simultaneous minor internal resorption/regrowth shown by arrows in Fig. 4b. Occurrence of internal twinning during growth of $\mathrm{P}$ diamond is displayed in Fig 4c.

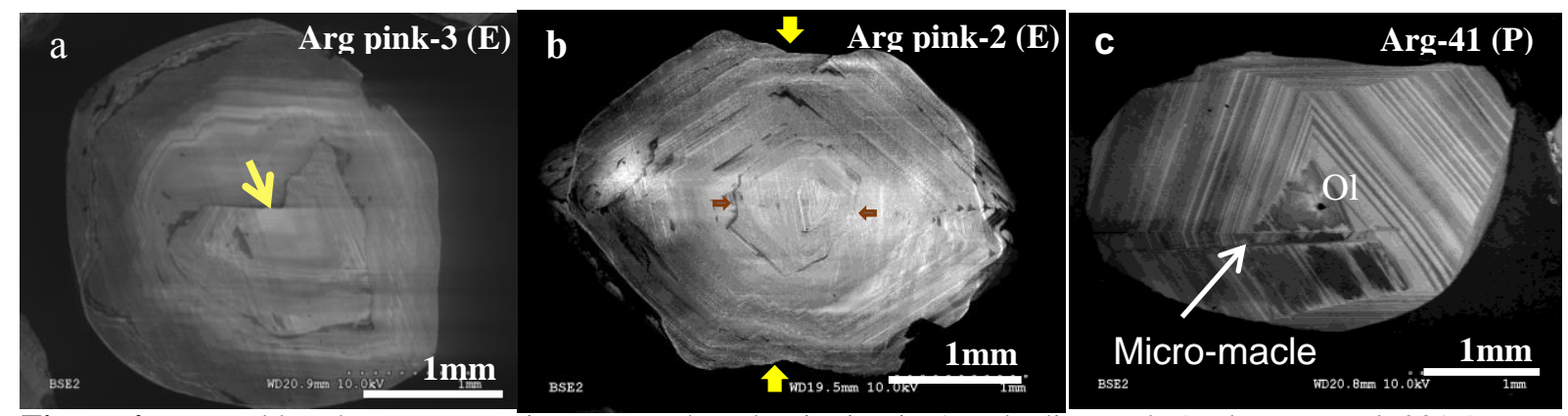

Figure 4: Internal breakages, resorption-regrowth and twinning in Argyle diamonds (Bulanova et al, 2017).

In agreement with previous observations, $\mathrm{N}$ concentration is greater in the core growth zones, relative to the rims of lithospheric $\mathrm{P}$ and $\mathrm{E}$ diamonds. However, this is not always the case (Fig 5), as different patterns can include (i) concentric octahedral zones with changing or oscillating $\mathrm{N}$ concentrations (Sese 1-58.8, Dvk 143, Mur-265); (ii) non-concentric heterogeneity, particularly in core zones (Mir1164). Model temperatures can be calculated from such data sets, and for zoned diamonds additional 
constraints on thermal history can be deduced (Kohn et al., 2016). Most sublithospheric stones are type II ( $\mathrm{N}$ free) diamonds.
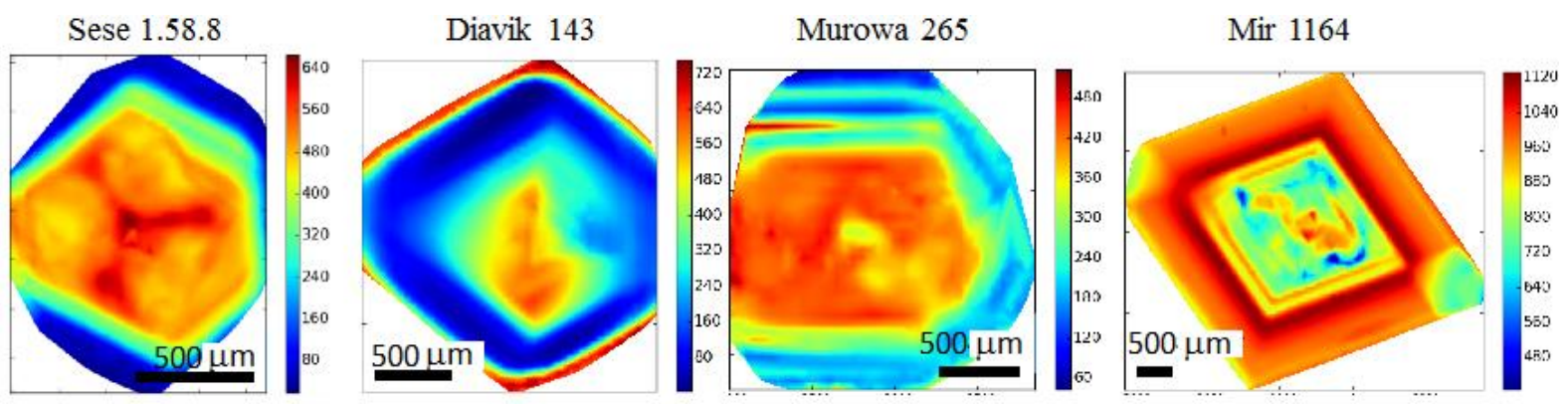

Figure 5: Distribution of $\mathrm{N}$ in typical lithospheric diamonds in FTIR maps. The scale bar represents ppm $\mathrm{N}$.

\section{Discussion and Conclusions}

We conclude that $\mathrm{P}$ and $\mathrm{E}$ lithospheric diamonds have mainly octahedral zonation, sometimes with sectorial, cubic or cubo-octahedral growth during initial stages of origin (Fig. 5). The majority of SL and Dachine diamonds show lack of zoning but are blocky, brecciated and deformed (Fig. 5).

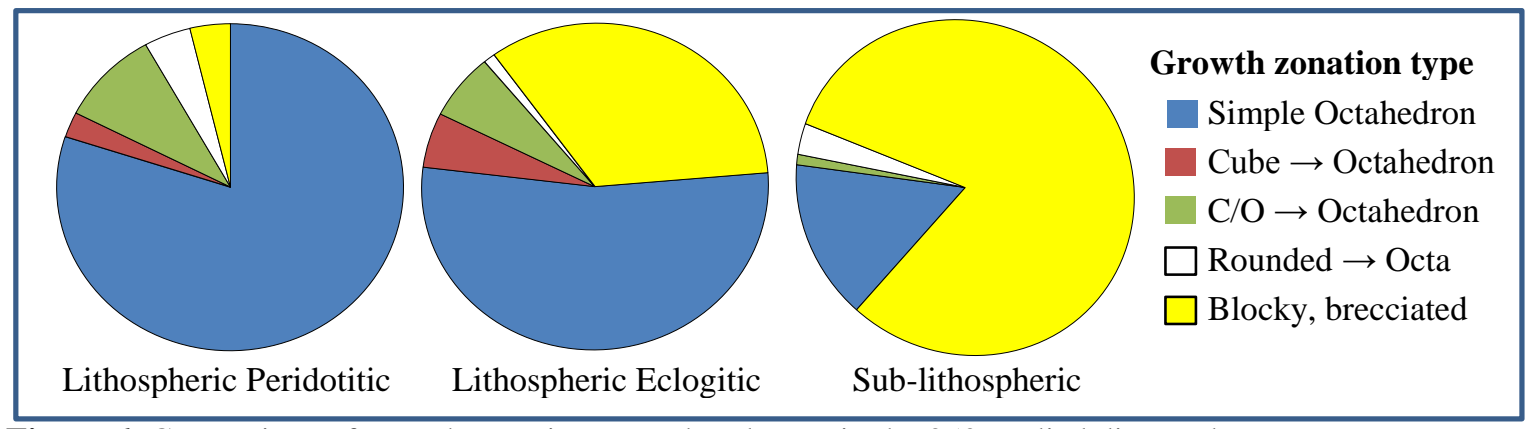

Figure 6: Comparison of growth zonation type abundances in the 350 studied diamonds

Therefore, internal structures in diamonds from different tectonic settings vary, recording variable formation conditions. Octahedral zonation in lithospheric $\mathrm{P}$ and $\mathrm{E}$ diamonds formed by layer by layer growth from fluids/melts of low to moderate degree of carbon supersaturation (Sunagawa, 1984), under relatively stable conditions in sufficient space where idiomorphic crystals can originate (Chernov, 1984). SL, Dachine, and Argyle E diamonds grew as metasomatic crystals during subduction processes from fluids of moderate to high degrees of carbon supersaturation, and in restricted spaces, such as veins and cracks. Geothermometry, based on N contents, aggregation state, and age relationships of the diamonds, shows that most lithospheric stones have temperatures corresponding with a $\sim 40 \mathrm{~mW} / \mathrm{m}^{2}$ model geotherm and a lithospheric keel depth of $\sim 180-200 \mathrm{~km}$. SL diamonds grew at depths ranging down to the Transition Zone and Lower Mantle.

\section{References}

Bulanova GP, Speich L, Smith CB, Gaillou E, Kohn SC, Wibberley E, Chapman JG, Howell D, Davy AT (2016) The unique nature of Argyle fancy diamonds: internal structure, paragenesis and reasons for color. In: Geoscience and Exploration of Rio Tinto's diamond deposits. Society of Economic Geologists, Inc., Special Publication (in press).

Chernov AA (1984) Modern crystallography III., Springer, New York, Tokyo. 517pp.

Kohn SC, Speich L, Smith CB, Bulanova GP (2016) FTIR thermochronometry of natural diamonds: a closer look. Lithos 265: 148-158

Smith CB, Walter MJ, Bulanova G, Mikhail S, Burnham A, Gobbo L, Kohn S (2016) Diamonds from Dachine, French Guiana: A unique record of early Proterozoic subduction. Lithos 265: 82-95.

Sunagawa I (1984) Morphology of natural and synthetic diamond crystals. In: Sunagawa, I., Materials Science of the Earth's interior. Terra Scientific Publishing, Tokyo, 303-330. 